\title{
Type 1 diabetes perioperative care: Preventing harm to patients
}

Follow this and additional works at: https://www.journal.acorn.org.au/jpn

Part of the Health Services Administration Commons, Health Services Research Commons, Perioperative, Operating Room and Surgical Nursing Commons, and the Surgery Commons

c) (i)

This work is licensed under a Creative Commons Attribution 4.0 License.

\section{Recommended Citation}

Munt, Rebecca (2020) "Type 1 diabetes perioperative care: Preventing harm to patients," Journal of Perioperative Nursing: Vol. 33 : Iss. 3 , Article 5.

Available at: https://doi.org/10.26550/2209-1092.1097

https://www.journal.acorn.org.au/jpn/vol33/iss3/5

This Article is brought to you for free and open access by Journal of Perioperative Nursing. It has been accepted for inclusion in Journal of Perioperative Nursing by an authorized editor of Journal of Perioperative Nursing. 


\section{Author}

Dr Rebecca Munt

PhD, Grad Cert Ed (High Ed), BN, RN, MACN

\section{Type 1 diabetes perioperative care: Preventing harm to patients}

Imagine you lived with a chronic condition that required you to make over 100 self-management decisions every day. Imagine you have been admitted to hospital for a day surgery procedure and the health professionals have refused your request for access to a medication you need for survival. Imagine that as a result of missing this medication you have ended up in an intensive care unit (ICU) with a life-threatening condition. The life-threatening condition is diabetic ketoacidosis (DKA) and the medication you needed is insulin, because you have type 1 diabetes (T1D).

Let's consider why a person with T1D entering the health care system for a simple day procedure can end up in ICU with a life-threatening condition. On admission to hospital, people with T1D are often required to relinquish responsibility for their usual self-management of their condition ${ }^{1,2}$. Furthermore, it is common practice for health professionals to take over T1D management from the individual in hospital ${ }^{2,3}$. However, people in hospital with diabetes are exposed to a variety of errors through health professionals' management of diabetes. These errors include insulin administration errors; inappropriate content, availability and timing of meals; and poor hypoglycaemia management 4 . As a result of these health professional errors a stay in hospital for a person with T1D can be a frightening experience because of the risk of harm they may be exposed to. In the UK in 2017, 1 in 25 inpatients with T1D developed DKA due to health professionals undertreating this patient group with insulin ${ }^{5}$. Not only does an episode of DKA extend the patients length of stay, which leads to additional financial cost to the hospital, the impact on the patient psychologically and physically is significant and can impact on the therapeutic relationship with health professionals.

One of the reasons diabetes management errors occur in hospital is because health professionals do not listen to the patient. Over time, people with T1D are known to become experts in their diabetes self-management through years of lived contextual experience ${ }^{6,7}$. Due to this lived contextual experience people with T1D are knowledgeable and capable of self-managing or contributing to making decisions about how their T1D should be managed in hospital2,8. Listening to the patient and learning about their usual T1D management is valuable in the prevention of diabetes mismanagement.

Errors also occur because health professionals are not routinely engaging people with T1D in discussions about their usual diabetes self-management. By not asking about usual T1D self-management, health professionals remain unaware of the preferences and priorities of diabetes management for the individual. Research on the selfmanagement experiences of people with T1D in hospital found the participants experienced limited opportunities for discussing their diabetes management with health professionals ${ }^{8}$. The participants reported experiencing limited discussion about T1D management in their pre-admission appointment, during their episode of hospital care, and around discharge planning. As a result of the limited discussions 
initiated by health professionals, the participants initiated discussions with health professionals about how their T1D would be managed in hospital. However, some participants felt judged, dismissed and even ignored by health professionals when they initiated such discussions. As a result of not being listened to and their perspective not being understood, patients feel distressed in hospital and unsafe? ${ }^{9}$. Furthermore, limited discussions around T1D led participants to believe their T1D was not important to the health professionals ${ }^{8}$.

\section{Effective communication between} health professionals and patients is a significant component of ensuring safe high quality health care ${ }^{10,11}$. A review of patients' experiences in Australian hospitals found reciprocal communication and information sharing was important to patients ${ }^{9}$. However, participants with T1D reported limited reciprocal communication and information sharing, which led them to view their interactions with health professionals negatively and impacted on their capacity to trust the health professionals ${ }^{8}$.

The lack of discussions initiated by health professionals with the patient about their T1D management may be a result of the recognised knowledge deficit that exists among generalist health professionals about diabetes management ${ }^{8}$. A number of reviewed studies found that generalist health professionals have knowledge deficiencies around diabetes management, with specific deficiencies in the use of insulin ${ }^{8}$. However, regardless of the health professional's discipline, they need to have knowledge about diabetes management for inpatients because diabetes can complicate the person's admission diagnosis ${ }^{12}$.
It is recognised that generalist health professionals cannot be experts in the detailed management of all complex conditions such as T1D ${ }^{13}$. While the rising complexity of care and the increase of people with chronic conditions place additional demands on the communication required of health professionals, poor communication is known to increase the risk of errors in health care. Therefore, effective communication is essential to the provision of quality and safe care ${ }^{11}$. In order to feel safe, patients need access to open, timely and accurate communication with health professionals about their care in hospital.

The opportunity to exchange ideas between health professionals and patients supports the ideals of patient participation in health care and a consumer-centred care focus. Castro et al. suggested that these ideals of patient participation and consumer-centred care have been 'buzz concepts for quite some time now ${ }^{14, \text { p.1924 }}$. These ideals indicate that patients are no longer just passive recipients of care but rather play an active role in making informed decisions about their own health care ${ }^{15,16}$. In essence, patient-centeredness is an approach to care that meets the patient's 'needs, values and beliefs' through understanding the patient's 'expectations, perceptions and experiences' of their care ${ }^{14,}$, p1929. In addition, patients' being actively involved in their health care reduces the gap between the experiential knowledge of the person and the health professionals' knowledge ${ }^{14}$.

Another reason for limited engagement by health professionals around T1D management in hospital is because of the reluctance to accept the expertise of the patient. Health professionals have obtained knowledge specific to their role through formal study and clinical experience. Traditionally, health professionals' knowledge is often viewed as authoritative because their knowledge is socially constructed as being both legitimate and dominant ${ }^{17}$. Consequently, those who have knowledge that is considered to be outside the conventional understanding of knowledge, such as those with a lived experience of T1D, may be viewed as having inferior knowledge. Patients with T1D who have in-depth knowledge of their diabetes encounter issues when their expertise is viewed as inappropriate in interactions with generalist health professionals because the person's expertise can be considered as 'noncompliant' by health professionals who are not diabetes specialists ${ }^{13}$. The issue is further exacerbated when generalist health professionals, despite their good intentions, block access to insulin and other supplies needed to safely manage T1D.

So what can be done better in the perioperative environment to reduce harm being caused to people with T1D undergoing surgery? There are local policies in place for managing T1D in the perioperative environment; however, the context of the individual still needs to be taken into consideration when planning care. For example, a person with T1D and gastroparesis, a potential complication of autonomic neuropathy, may need an alteration to the usual recommended fasting time due to delayed gastric emptying. In addition, Standards for Perioperative Nursing in Australia (the ACORN Standards) include the ACSQHC National Safety and Quality Health Service (NSQHS) standards of communicating for safety, partnering with consumers, and medication safety as required areas of competence in multiple nursing roles in perioperative nursing ${ }^{18}$.

In relation to communicating for safety there are a number of actions 
that can be undertaken. Firstly, find out if the person has diabetes, what type of diabetes they have (don't make assumptions based on medications that have been prescribed) and ask about their usual treatment. Improving care and keeping patients safe starts with improving communication. People with diabetes should be involved in discussion to plan their diabetes management in hospital for any elective admission from the preadmission stage all the way through to the discharge of the patient ${ }^{4}$. Health professionals need to seek information at the beginning of their interaction with a person with T1D to determine whether the person with diabetes wishes to self-manage during their admission ${ }^{4}$. The initial discussion represents an opportunity to ensure appropriate support can be implemented, for the entire admission, that can assist in the prevention of diabetes management errors along with increased patient satisfaction with their care and an improved overall experience while in hospital. In addition, discussion around diabetes management allows for the health professional to develop an understanding of the person with T1D's preferences for their care which can result in the health professional being able to advocate for the person when they are not being listened to by other health professionals.

Partnering with consumers through shared decision making and encouraging consumer participation in their care is essential for safety. To truly partner with consumers, health professionals need to value the expertise and knowledge of the patient as being equal and complimentary to their own knowledge ${ }^{14}$. Recognition and acknowledgement of the patient's experiential knowledge as being able to provide a complementary contribution to health care is required to foster collaboration and to integrate patients into health care teams ${ }^{19}$. Health professionals also need to recognise that the person with T1D and their expertise are valuable resources in the management of T1D in hospital.

Medication safety is essential when considering insulin. In Australia, insulin is considered a high risk medication (HRM) because the risk of the medicine causing significant harm to the patient, or death, is high $^{20}$. While insulin is not necessarily a medication where more errors are made, it is a medication with a narrow therapeutic window so the consequence of an error with insulin can lead to significant harm, including death. Training about the safe use of insulin, and the main harms associated with diabetes and how they can be prevented should be mandatory for all health professionals. If the patient is on insulin consider their need to continue insulin, as ceasing or withholding insulin can cause serious harm, such as DKA, to the patient. If there is uncertainty around the management of insulin for a patient in the perioperative environment, asking the patient and consulting with health professionals with diabetes expertise can reduce the potential risk of harm. According to Flanagan et $\mathrm{al}^{4}$ a key strategy to improve the safety of insulin administration in hospital is to allow the person with diabetes who has the appropriate skills to self-manage their insulin. An additional strategy is for health professionals to be aware of knowing what they don't know and seeking expertise from others about diabetes management.

In summary, people with T1D who are in hospital need to be able to collaborate with health professionals to negotiate plans of care to keep them safe. Patient participation in care is happening and people with T1D are actively participating in their diabetes management. However, consumer-centred care needs to be improved as a way of ensuring that people are safe in hospital and that the individualised needs of the person with T1D are being met. In order to provide safe and collaborative care for people with T1D in hospital, health professionals need to acknowledge the selfmanagement expertise of these people and use this expertise when negotiating care.

\section{References}

1. Cohen L, Sedhom L, Salifu M, Friedman E. Inpatient diabetes management: Examining morning practice in an acute care setting. Diabetes Educ 2007;33(3):483-492.

2. Mabrey M, Setji T. Patient self-management of diabetes care in the inpatient setting: Pro. J Diabetes Sci Technol 2015;9(5):1152-1154.

3. Shah A, Rushakoff R. Patient selfmanagement of diabetes care in the inpatient setting: Con. J Diabetes Sci Technol 2015;9(5):1155-1157.

4. Flanagan D, Dhatariya K, Kilvert A, Joint British Diabetes Societies (JBDS) for Inpatient Care group and guidelines writing group. Self-management of diabetes in hospital: A guideline from the Joint British (JBDS) for Inpatient Care group. Diabet Med 2018;35:992-996.

5. Diabetes UK. Making hospitals safe for people with diabetes [Internet]. London: Diabetes UK; 2018 [cited 2020 August 12]. Available from: www.diabetes.org.uk/ resources-s3/2018-10/Making\%20 Hospitals\%20safe\%20for\%20people\%20 with\%20diabetes_FINAL.pdf

6. Paterson B, Thorne S. Developmental evolution of expertise in diabetes selfmanagement. Clin Nurs Res 2000;9(4):402419

7. Thorne S, Ternulf Nyhlin K, Paterson B. Attitudes toward patient expertise in chronic illness. Int J Nurs Stud 2000;37(4):303-311.

8. Munt R. Type 1 diabetes self-management in hospital: A constructivist grounded theory. PhD thesis. Adelaide: Flinders University; 2020.

9. Harrison R, Walton M, Manias E, Mears S, Plumb J. Patients experiences in Australian hospitals: A systematic review of the evidence. Aust Health Rev; 2017;41(4):419-435. 
10. ledema R, Manidis M. Patient-clinician communication: An overview of relevant research and policy literatures. Sydney; Australian Commission on Safety and Quality in Health Care and Centre for Health Communication, University of Technology Sydney; 2013.

11. Australian Commission on Safety and Quality in Health Care (ACSQHC). Communicating with your healthcare provider when you are in hospital, an information sheet for consumers [Internet] Sydney: ACSQHC; 2016 [cited 2020 August 12]. Available from: www.safetyandquality. gov.au/wp-content/uploads/2016/11/ Information-sheet-for-consumersCommunicating-with-your-healthcareprovider.pdf.

12. Van Zyl D, Rheeder, P. Survey of knowledge and attitudes regarding diabetic inpatient management by medical and nursing staff at Kalafong Hospital. Journal of Endocrinology, Metabolism and Diabetes of South Africa 2008:13(3):90-97.
13. Snow R, Humphrey C, Sandall, J. What happens when patients know more than their doctors? Experiences of health interactions after diabetes patient education: A qualitative patient-led study. BMJ Open 2013;3:e003583.

14. Castro E, Van Regenmortel T, Vanhaecht K, Sermeus W, Van Hecke, A. Patient empowerment, patient participation and patient-centeredness in hospital care: A concept analysis based on a literature review. Patient Educ Couns 2016;99(12):19231939.

15. World Health Organization (WHO) Regional Office for Europe. Exploring patient participation in reducing health-carerelated safety risks. Copenhagen: WHO Regional Office for Europe; 2013.

16. Sahlstrom M, Partanen P, Azimirad M, Selander T, Turunen H. Patient participation in patient safety - An exploration of promoting factors. J Nurs Manag 2018;27(1):84-92
17. Jordon B. Authoritative knowledge and its construction. In: Davis-Floyd R, Sargent C (eds), Childbirth and Authoritative Knowledge: Cross-Cultural Perspectives. Berkeley: University of California Press;1997, pp. 55-79.

18. Australian College of Perioperative Nursing (ACORN). Standards for Perioperative Nursing in Australia. $16^{\text {th }}$ ed Volume 2 Professional Standards. Adelaide: ACORN; 2020.

19. Pomey M-P, Ghardiri D, Karazivan P, Fernandez N, Clavel N. Patients as partners: A qualitative study of patients' engagement in their health care. PLoS One 2015;10(4):1-19.

20. Australian Commission on Safety and Quality in Health Care (ACSQHC). High risk medicines [Internet]. Sydney: ACSQHC; 2019 [cited 2020 August 12]. Available from: www.safetyandquality.gov.au/our-work/ medication-safety/high-risk-medicines. 